\title{
P Adhikari
}

\section{New Editorial Board and Peer Reviewers of Nepalese J ENT Head Neck Surg}

Nepalese Journal of ENT Head \& Neck Surgery

\section{Correspondence to}

Dr. Prakash Adhikari, Managing Editor, Nepalese Journal of ENT Head \& Neck Surgery, Kathmandu, Nepal

Email: njenthns@gmail.com /

drprakashadhikari@hotmail.com

Finally, we came with second issue of Nepalese Journal of ENT Head \& Neck Surgery (Nepalese J ENT Head Neck Surg), an official biannual publication of Society of Otolaryngologists of Nepal. We got ISSN number both on print and online in this issue. And we are in the process of indexation with various agencies such as NepJOL, AsiaJOL, HINARI, NHRC, Index Copernicus, EBSCO, DOAJ etc.

The second issue is memorable to me as my appointment as a managing editor of this prestigious journal. I have been doing audit on accuracy of references in different national and international journals and found ample amount of references to be incorrect. To address this issue, the editorial board has decided to check the references by the managing editor and work as a reference editor too. I hope the references of our journal will be more accurate by this appointment.

In this issue, we have also added international peer reviewers besides national reviewers. On behalf of the editorial board, I would like to acknowledge all of our pertinent peer reviewers. Peer reviewers of this issue are:

1. Prof. Prepageran, Malaysia

2. Prof. Luiz Alberto Alves Mota, Brazil

3. Dr. Iqbal Khayira, Pakistan

4. Prof. Bimal Kumar Sinha, Nepal

5. Prof. Hari Bhattarai, Nepal

6. Prof. Bibhu Pradhan, Nepal

7. Prof. Chop Lal Bhusal, Nepal

8. Dr. Toran KC, Nepal

9. Dr. Tapas Pramanik, India

10. Dr. Anjan Shrestha, Nepal

11. Dr. Yogesh Neupane, Nepal

Lastly, the editorial board welcomes all types of articles via online submission and invites interested candidates to join our journal as a peer reviewer by submitting their CV (including publications in medical journals) at njenthns@gmail.com . 